\author{
Andrzej Pisowicz \\ (D) https://orcid.org/0000-0002-9835-416X \\ UNIWERSYTET JAGIELLOŃSKI
}

\title{
TAJEMNICZY NAPIS \\ Z OBRAZU MATKI BOSKIEJ ORMIAŃSKIEJ W KAMIEŃCU PODOLSKIM
}

\begin{abstract}
Abstrakt: Na podstawie publikacji Jacka Chrząszczewskiego autor koryguje odczyt napisu na cudownym obrazie Matki Boskiej Kamienieckiej z kościoła ormiańskiego św. Mikołaja w Kamieńcu Podolskim dokonany przez edytorów niedawnego niemieckiego tłumaczenia dzieła Minasa Byżyszkianca pt. Podróż do Polski z 1830 roku.
\end{abstract}

Słowa kluczowe: Kamieniec Podolski, Ormianie polscy, Minas Byżyszkianc

Chodzi tu o obraz, który przez kilka wieków (z przerwami) znajdował się w środku ołtarza kościoła św. Mikołaja w mieście Kamieniec Podolski, leżącym w zakolu rzeki Smotrycz (lewy dopływ Dniestru), na terenach należących dawniej do Królestwa Polskiego, a obecnie do Ukrainy. Obrazowi owemu przypisywano liczne cuda. Był przedmiotem kultu dla chrześcijan trzech obrządków, którzy mieszkali w Kamieńcu Podolskim: Ormian, Polaków i Rusinów. Ormianie polscy w XVII wieku przystąpili do unii z Kościołem rzymskim.

W 1820 roku obraz ów obejrzał ormiański uczony, zakonnik z kongregacji Mechitarystów, Minas Byżyszkianc. W roku 1830 wydał on w Wenecji napisaną po staroormiańsku (czyli tzw. grabarem) książkę pt. Podróż do Polski ${ }^{1}$. Opisał w niej miejscowości i kościoły polskich Ormian, leżące na terenach należących

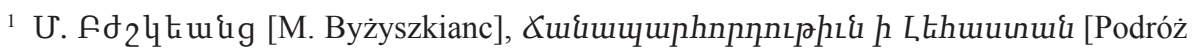
do Polski], પ,kGtiunhl [Wenecja] 1830. 
wówczas (po rozbiorach Polski) do Austrii i Rosji. W zaborze austriackim znajdowały się m.in.: Lwów, Stanisławów, Kuty. Natomiast po przekroczeniu granicy austriacko-rosyjskiej o. Byżyszkianc zwiedził należące wówczas do Rosji miejscowości, w których istniały zabytki ormiańskie. Najważniejszą z nich był Kamieniec Podolski. W roku 2019 wydawnictwo Böhlau Verlag Wien Köln Weimar opublikowało niemiecki przekład książki Minasa Byżyszkianca, zamieszczając na okładce, zmieniony w stosunku do oryginału, opisowy tytuł: Der Reisebericht des Minas Bžškeanc ${ }^{c}$ über die Armenier im östlichen Europa (1830). Autorami przekładu, wstępu i przypisów są Bálint Kovács i Grigor Grigoryan (współpracował z nimi Alexandr Osipian) ${ }^{2}$.

W paragrafie 215 dzieła Minasa Byżyszkianca czytamy na temat tytułowego obrazu Matki Boskiej Ormiańskiej z Kamieńca Podolskiego, że:

Cudowny obraz Matki Boskiej znajduje się w środku ołtarza. Jest umocowany w mosiężnym oknie, które jest otwierane w każdą sobotę ${ }^{3}$ [...] Kształt owego cudownego obrazu jest kwadratowy. Każdy jego bok ma długość mniej więcej jednego łokcia ${ }^{4}$. Jest to olśniewająco piękny obraz [...], cały pomalowany na srebrno ${ }^{5}$. Tylko świetliste oblicza Matki Boskiej i Dzieciątka Jezus promienieją ${ }^{6}$. W promieniach rozchodzących się od twarzy Matki Boskiej widoczny jest kolisty napis utworzony ze złotych liter, którego do tej pory nikt nie zdołał odczytać. Jedni kojarzą te litery z alfabetem hebrajskim, pozostali uważają, że to jest jakieś inne (nie

2 Der Reisebericht des Minas Bžškeancc über die Armenier im östlichen Europa (1830), wyd. B. Kovács, G. Grigoryan, współpraca A. Osipian, Wien-Köln-Weimar 2019.

3 Termin „okno” w oryginale Byżyszkianca jest oddany ormiańskim wyrazem upuunnıhu\{, czyli etymologicznie: „otwór (dziura) w ścianie”. Według Jacka Chrząszczewskiego chodzi tu zapewne o niszę w głównym ołtarzu kościoła św. Mikołaja, w której umieszczony był obraz, ujętą w mosiężną ramę i być może odsłanianą i zasłanianą zasuwą, podobnie jak obraz Matki Boskiej Częstochowskiej na Jasnej Górze.

${ }^{4}$ Dawna miara długości „łokieć”, tu w oryginale M. Byżyszkianca: quuqunı\{. Według informacji uzyskanej od Jacka Chrząszczewskiego „około roku 1820, gdy M. Byżyszkianc odwiedził Kamieniec Podolski, w Królestwie Polskim używany był łokieć nowopolski, przyrównywany do 288 linii paryskich, z których każda miała $2 \mathrm{~mm}$ długości, a więc liczący $57,6 \mathrm{~cm}$. Nie wiemy jednak, czy M. Byżyszkianc posłużył się tą miarą długości, gdyż wysokość obrazu jest zbliżona raczej do dwóch takich łokci. Wiemy natomiast, że obraz Matki Boskiej Ormiańskiej z Kamieńca Podolskiego nie ma kształtu kwadratowego, lecz kształt prostokąta stojącego o stosunku boku do podstawy około 5 do 4”.

5 Fragment tekstu Byżyszkianca, opisujący obraz jako: „cały pomalowany na srebrno”, Jacek Chrząszczewski komentuje następująco: „Na podstawie zachowanych fotografii archiwalnych wiemy, że obraz Matki Boskiej Ormiańskiej w kościele św. Mikołaja w Kamieńcu Podolskim był niegdyś przykryty sukienkami, koronami i licznymi wotami srebrnymi. Samo oryginalne tło obrazu zostało jednak pozłocone".

${ }^{6}$ Odnosząc się do relacji M. Byżyszkianca o tym, że „oblicza Matki Boskiej i Dzieciątka Jezus promienieją”, J. Chrząszczewski potwierdza, że: „Głowy Marii i Chrystusa na tym obrazie otoczono nimbami promienistymi”. 
hebrajskie) pismo7. Ja [dosłownie Byżyszkianc pisze: „my”] wspiąłem się osobiście w górę, by z bliska skopiować ów napis. Stwierdziłem, że to są dawne litery ormiańskiego alfabetu, ale zapisane nietypowo, według innej zasady niż normalne pismo ormiańskie ${ }^{8}$.

Dalej o. Byżyszkianc zamieszcza w swej książce na końcu paragrafu 215 przerys (kopię) owego napisu'. Nie aspiruje jednak do jego interpretacji, co nasuwa wątpliwości co do języka, w którym napis został sporządzony. Oto reprodukcja owego przerysu:

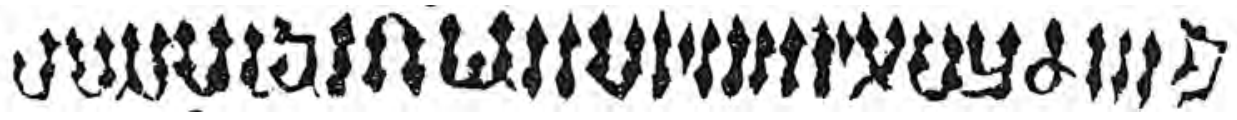

Dopiero pod koniec XX wieku krakowski architekt i historyk sztuki Jacek Chrząszczewski w książce zatytułowanej Ormiańskie świątynie na Podolu ${ }^{10}$ rozszyfrował ów tajemniczy napis. Stwierdził mianowicie:

Zapewne pokrywająca obraz srebrna sukienka sprawiła, iż napis ten nie został dotychczas poprawnie odczytany. Dziś jego odczytanie nie stanowi problemu! Gotycką minuskułą zapisano początkowe wersy antyfony brewiarzowej: „Regina coeli laet[are] alleluia, quia quem meruisti portare al1[elui]a [Królowo nieba bądź radosna alleluja, gdyż zasłużyłaś nosić Tego alleluja]. Wzdłuż dolnej krawędzi obrazu przebiega drugi napis: O Maria Mater Cristi Virgo [O Mario matko Chrystusa dziewico] ${ }^{11}$.

W tym samym przypisie J. Chrząszczewski informuje (dzięki pomocy Jana Gadomskiego), iż obraz Matki Boskiej Ormiańskiej z Kamieńca Podolskiego z biegiem czasu został przeniesiony „do Kijowskiego Państwowego Muzeum Sztuki Wschodniej i Zachodniej (nr inw. 168). W roku 1995 przeprowadzono jego konserwację w Pracowni Konserwacji Malarstwa Ukraińskiego Centrum Konserwacji w Kijowie"12. Na sąsiedniej stronie tejże publikacji jest zamieszczona czarno-biała reprodukcja omawianego tu obrazu wykonana „z pocztówki, sprzed $1918 \mathrm{r}$." ${ }^{13}$. Sam obraz jest tu słabo widoczny ze względu na liczne przesła-

7 Wspomniany przez Byżyszkianca „kolisty napis” według Jacka Chrząszczewskiego: „Znajduje się w otoku promienistego nimbu nad głową Matki Boskiej i składa się ze złotych liter gotyckich".

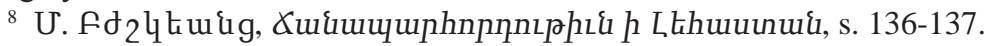

9 Ibidem, s. 137.

10 J. Chrząs zczewski, Ormiańskie światynie na Podolu, Kraków 1998, s. 37-39, przypis 136; por. też streszczenie angielskie na s. 61, przypis 3 .

11 Ibidem, s. 39.

12 Ibidem.

13 Ibidem, s. 38. 
niające go wota. Natomiast ilustracja nr 25 (umieszczona w dalszej części książki J. Chrząszczewskiego) przedstawia tenże obraz już bez wotów. Reprodukcja została przedrukowana z książki Aleksandra Prusiewicza ${ }^{14}$. Informacja w języku angielskim pt. The Picture of the Armenian Holy Mary, zawierająca angielski przekład wyżej cytowanych łacińskich napisów, została zamieszczona w obszernym streszczeniu angielskim we wspomnianej tu książce J. Chrząszczewskiego ${ }^{15}$. Te same informacje o treści napisów łacińskich, umieszczonych na obrazie Matki Boskiej Ormiańskiej, zostały powtórzone w następnej książce wspomnianego autora (najlepiej widoczne są one na kolorowej ilustracji nr 134) ${ }^{16}$.

Podkreślam te szczegóły w związku z niezrozumiałym pominięciem obu książek Jacka Chrząszczewskiego przez autorów wspomnianego wyżej niemieckiego przekładu dzieła Minasa Byżyszkianca. Co więcej, jej edytorzy podają inną (!) wersję napisu znad głowy Matki Boskiej z obrazu, który opisał M. Byżyszkianc. Są to mianowicie, ich zdaniem, słowa: Ave Maria, gratia plena, Dominus tecum (w thumaczeniu niemieckim: „Gegrüßet seist du, Maria, voll der Gnade, der Herr ist mit dir”) oraz O Marie mater Dei Christi („O Maria, Mutter des Gottes Christus") ${ }^{17}$.

Nasuwa się tu pytanie: skąd ta różnica w interpretacji tego samego łacińskiego napisu, od dawna już znanego w literaturze przedmiotu? Jacek Chrząszczewski jednoznacznie informuje, że źródłem jego odczytu była dokładna analiza z autopsji obrazu Matki Boskiej z Dzieciątkiem, który znajduje się dziś w zbiorach kijowskiego Muzeum im. Bohdana i Warwary Chanenko (obecna nazwa dawnego Kijowskiego Państwowego Muzeum Sztuki Wschodniej i Zachodniej). Natomiast B. Kovacs i G. Grigoryan nie podają źródła swej wersji. Powołują się jedynie, na końcu swego przypisu, na dwie publikacje, w których nie ma żadnych cytatów łacińskich odnoszących się do interesującego nas obrazu ${ }^{18}$.

14 A. Prusiewicz, Kamieniec Podolski. Szkic historyczny, Kijów-Warszawa 1915.

15 J. Chrząszczewski, Ormiańskie światynie, s. 61, przypis 3.

${ }_{16}$ Id em, Kościoły Ormian polskich. Katalog zabytków ormiańskich, „Res Publica Multiethnica”, 1, Warszawa 2001, s. 42, przypis 68 oraz ilustracje 20-22, 134 (ta ostatnia w kolorze).

17 Der Reisebericht des Minas Bžškeancc, s. 210, przypis 253.

18 I. Hayuk, The Unknown about the Well-known. The Issue of the Attribution of Some Armenian Wonder-working Icons from the Cathedral of Assumption of the Holy Virgin in Lviv, „Series Byzantina. Studies on Byzantine and Post-Byzantine Art”, 15, 2017, s. 107-121; W. Deluga, Studies on Armenian Art in Poland at the Turn of the 19th Century, w: Die Kunst der Armenier im östlichen Europa, red. M. Dmitrieva, B. Kovács, Köln-Weimar-Wien 2014, s. 27-34. 


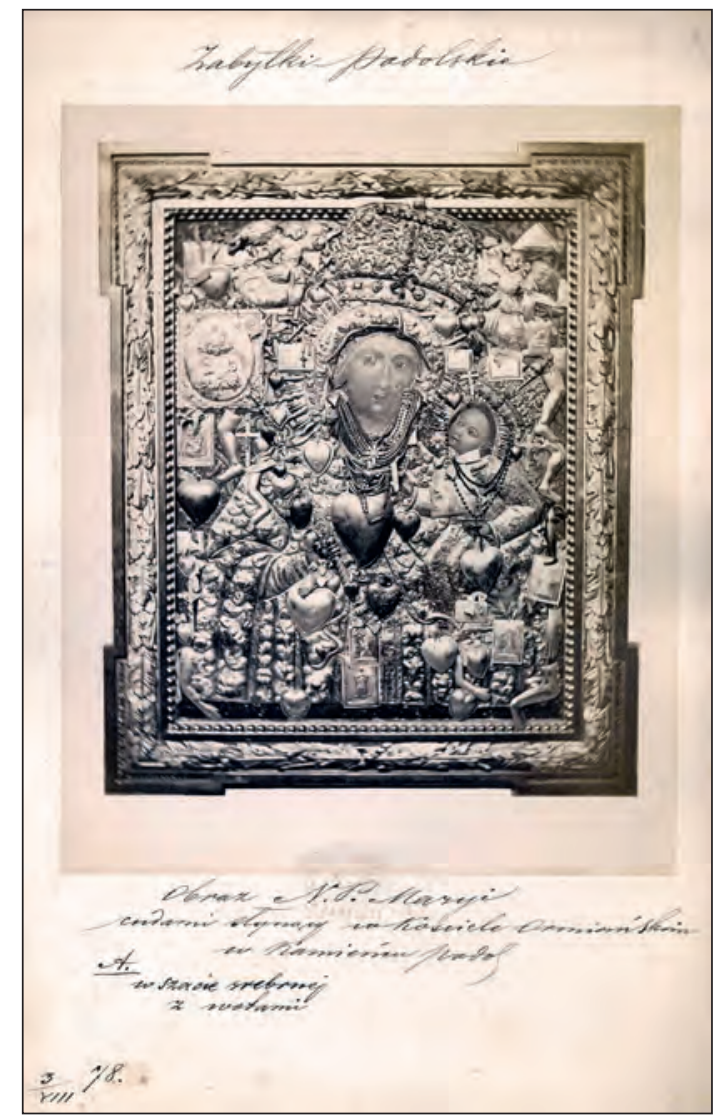

Michał Greim, Obraz Matki Boskiej Ormiańskiej w Kamieńcu Podolskim, 3 sierpnia 1878, fotografia, odbitka albuminowa, napis u dołu: „Obraz N.P. Maryi cudami słynący w Kościele Ormiańskim w Kamieńcu Podo[lskim] A. w szacie srebrnej z wotami, 3/VIII 1878"; Biblioteka Naukowa PAU i PAN w Krakowie, Zbiory Specjalne, sygn. 12 219; dar Michała Greima dla Komisji Antropologicznej Polskiej Akademii Umiejętności; numer inwentarza: BZS.RKPS.12219.k.36; digitalizacja: PAU, projekt PAUart www.pauart.pl, domena publiczna. 


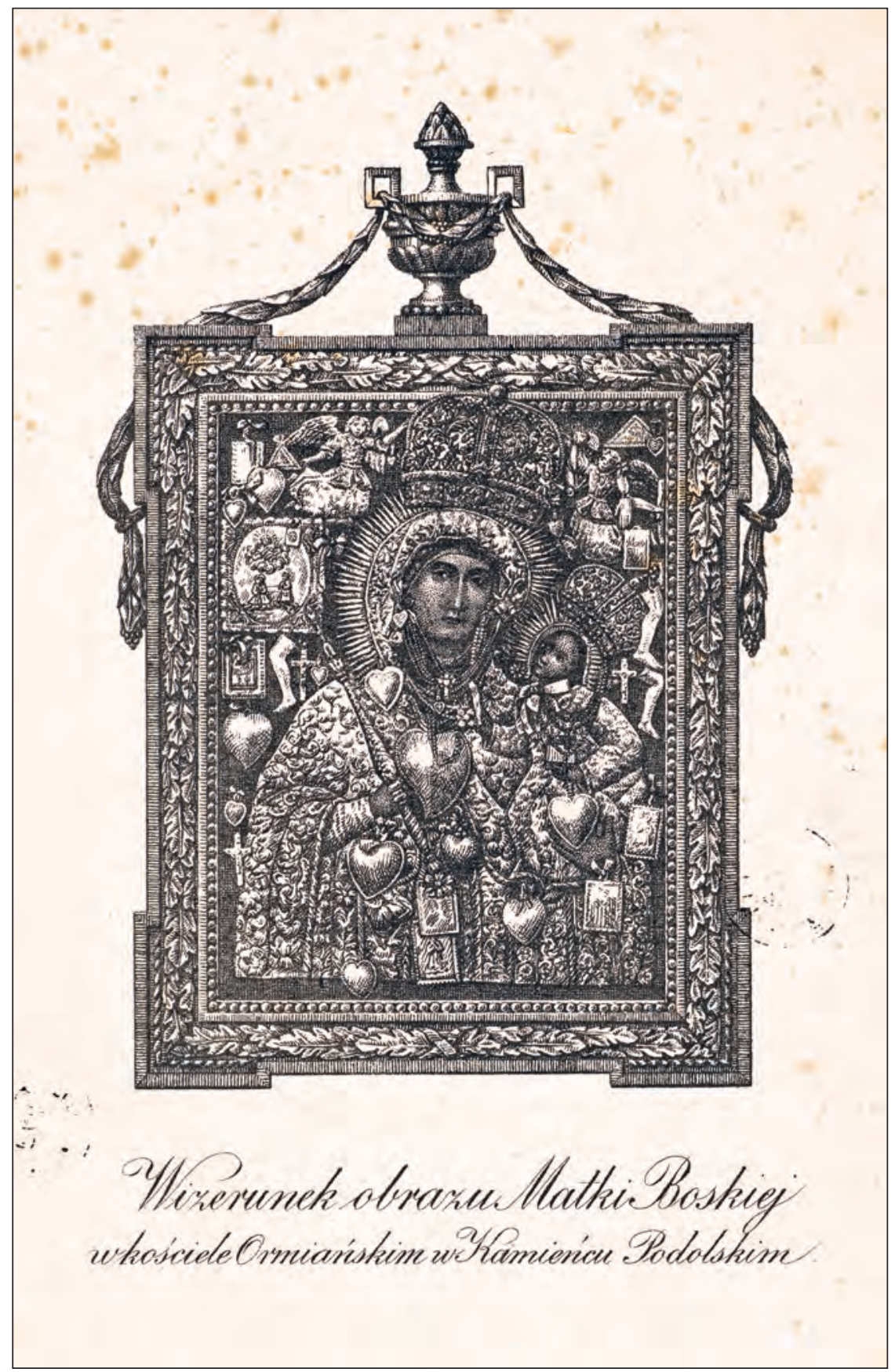

2. Matka Boska Kamieniecka z kościoła ormiańskiego pod wezwaniem św. Mikołaja w Kamieńcu Podolskim, litografia, XIX wiek, Muzeum Narodowe w Krakowie, nr inwentarzowy MNK III-ryc.-43413 


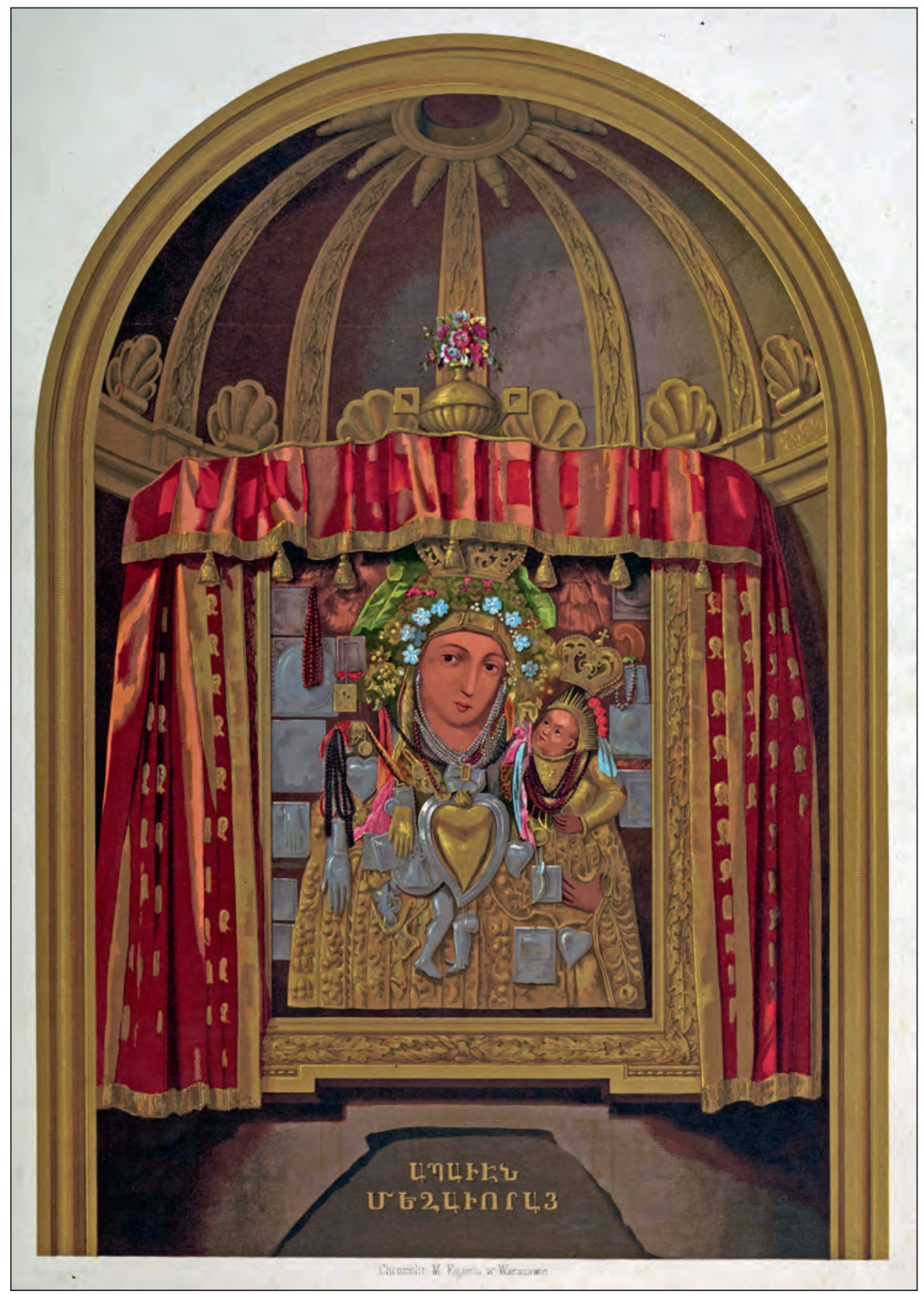

3. Matka Boska Kamieniecka z kościoła ormiańskiego pod wezwaniem św. Mikołaja w Kamieńcu Podolskim, chromolitografia, Maksymilian Fajans, Warszawa, 2 połowa XIX wieku, Muzeum Narodowe w Krakowie, nr inwentarzowy MNK III-ryc.-11440 


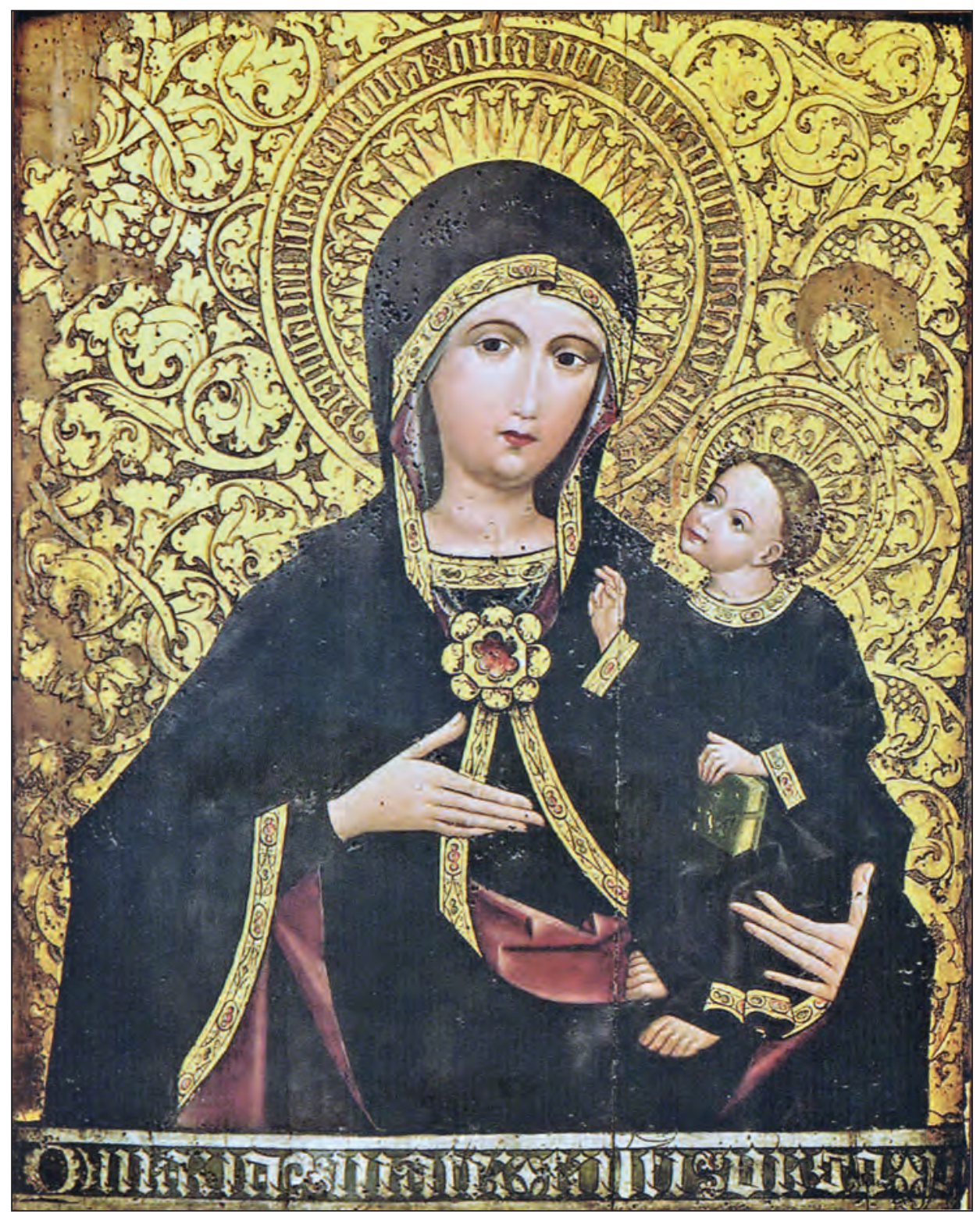

4. Matka Boska Kamieniecka z kościoła ormiańskiego pod wezwaniem św. Mikołaja w Kamieńcu Podolskim, stan po konserwacji, Muzeum Sztuki im. B. i B. Chanenków w Kijowie, sygn. ЖБ-130 


\title{
Bibliografia
}

\section{Źródla drukowane}

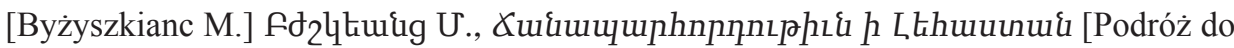
Polski], પ,tutunhl [Wenecja] 1830

Der Reisebericht des Minas Bžškeanc über die Armenier im östlichen Europa (1830), wyd. B. Kovács, G. Grigoryan, współpraca A. Osipian, Wien-Köln-Weimar 2019

\section{Opracowania}

Chrząszczewski J., Kościoły Ormian polskich. Katalog zabytków ormiańskich, „Res Publica Multiethnica", 1, Warszawa 2001

Chrząszczewski J., Ormiańskie światynie na Podolu, Kraków 1998

Deluga W., Studies on Armenian Art in Poland at the Turn of the 19th Century, w: Die Kunst der Armenier im östlichen Europa, red. M. Dmitrieva, B. Kovács, S. Troebst, KölnWeimar-Wien 2014, s. 27-34, https://doi.org/10.7788/boehlau.9783412212162.27

Hayuk I., The Unknown about the Well-known. The Issue of the Attribution of Some Armenian Wonder-working Icons from the Cathedral of Assumption of the Holy Virgin in Lviv, ,Series Byzantina. Studies on Byzantine and Post-Byzantine Art”, 15, 2017, s. $107-121$

Prusiewicz A., Kamieniec Podolski. Szkic historyczny, Kijów-Warszawa 1915

Andrzej Pisowicz, Mysterious writing from the picture of the Armenian Mother of God in Kamieniec Podolski (Kamianets-Podilskyi)

\begin{abstract}
The author, on the basis of Jacek Chrząszczewski's publications, corrects reading of the writing left on the miraculous picture of the Kamieniec Mother of God from the Armienian church of St Nicholas in Kamieniec Podolski (KamianetsPodilskyi), made by editors of the recent German translation of Minas Bzhshkyants' work Podróż do Polski [Journey to Poland] dated at 1830.
\end{abstract}

Keywords: Kamieniec Podolski (Kamianets-Podilskyi), Polish Armenians, Minas Bzhshkyants

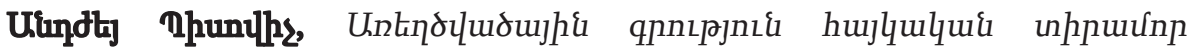

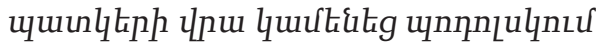

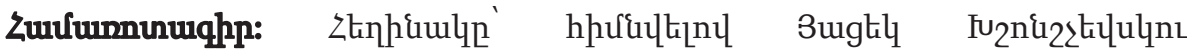

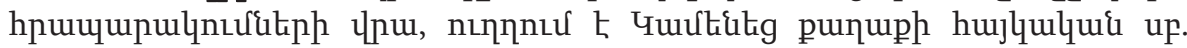

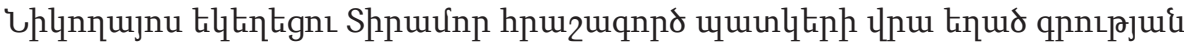

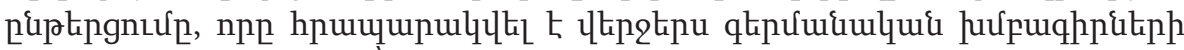

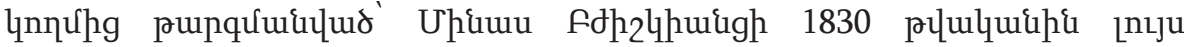

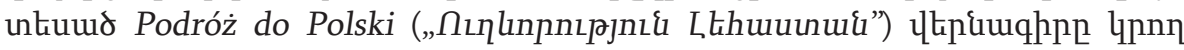

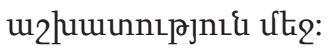

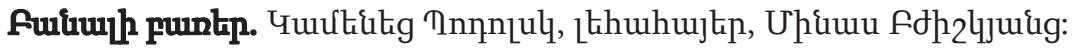

